\title{
Memória da Faculdade de Filosofia (1934-1994)
}

MIRIAM LIFCHITZ MOREIRA LEITE

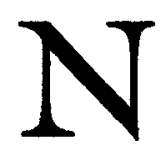

o dia 25 de janeiro de 1994, a Faculdade de Filosofia completou 60 anos. A mençáo abreviada e corriqueira da Faculdade de Filosofia pretende aglutinar suas denominaçóes - Faculdade de Filosofia, Ciências e Letras da Universidade de São Paulo e Faculdade de Filosofia, Letras e Ciências Humanas da USP, resultante da Reforma de 1969.

Essa memória tem de ser desembaraçada dos diferentes filos que a compóe - a das três populaçóes flutuantes de alunos, professores e funcionários, a de seções e departamentos que, em diferentes momentos, reuniram-se em meadas, novelos e carretéis ou desfizeram-se em franjas. A diversidade de Faculdades de Filosofia vividas forma a memória da instituição, através de consciência de seus membros ativos e inativos, na qual causas e fins tornam a se embraçar e o tempo, pelo esquecimento, desfaz arestas e idiossincrasias, ao intensificar lembranças da juventude e da maturidade.

\section{Os espaços}

Uma tentativa de periodizar a Memória esbarra nessa multiplicidade de aspectos, entre os quais, os diferentes espaços ocupados, a densidade desses espaços, o relacionamento com a cidade de São Paulo e os marcos da História Oficial não podem ser esquecidos.

Apesar da aguda consciência que alguns de seus alunos e professores manisfestaram a respeito de seus espaços e tempos vividos, este trabalho considera apenas uma combinaçáo de lembranças, que se apoiam umas nas outras, embora não sejam as mesmas que as de cada uma delas. Na colocaçáo de Maurice Halbwachs (1990:53) "a memória coletiva envolve as memórias individuais, mas não se confunde com elas".

À lembrança dos espaços ocupados e dos anos vividos, o trabalho da Memória tem de acrescentar as linhas de pesquisa e suas dimensóes educacionais, como a alma revelada às condiçóes materiais da instituiçáo. 
Como Marc Bloch respondeu ao filho: "Somos os vencidos provisórios de um destino injusto" e Cecília Meireles acrescentou: "Que faremos errantes, entre as invençóes dos Deuses?"

O trabalho da Memória vai acrescentando e desfazendo imagens gravadas de pessoas, livros, laboratórios, corredores e salas, onde o convívio de número variável de anos seguidos ou alternados inscreveu-se com tonalidades e intensidade diversas, na documentação escrita, em entrevistas e depoimentos reunidos. Aos documentos específicos, como regimentos, regulamentos e estatutos, acrescentaram-se anuários, guias, relatórios de atividades, balanços parciais, projetos, revistas e artigos que, comprimidos com livros de escrituração e fichários dos arquivos mortos, fotografias, recortes de jornal e programas de ensino, produzem um documentário do qual os problemas atuais da Faculdade podem extrair momentos e fases decisivas.

\section{A memória}

$\mathrm{O}$ artesanato arquivístico não dá conta das formas e fluidez de comportamento e pensamentos, nem da dinâmica social das instituições resultantes do convívio e dos conflitos de uma populaçáo flutuante heterogênea, com diferentes padróes culturais e alteraçóes variáveis.

A memória dá mais importância à reflexão sobre os fatos que à descrição. Insere o indivíduo na memória coletiva, fornecendo uma mistura variável de dados concretos, num labirinto de imaginário coletivo, composto por quadros do passado e reflexóes atuais.

Nas primeiras décadas, a Faculdade de Filosofia foi dominada pela Ciência Positiva a serviço do Estado. Mais tarde, a profissionalizaçăo e o ensino secundário dominaram as aspirações de alunos e professores. Durante décadas, pairou sobre a instituição a necessidade de conjugação de ensino e pesquisa. A importância dada ao objeto e ao método de cada ciência era estabelecido pelos seus limites. Agora, começa a confluir para a necessidade e para os problemas da interdisciplinaridade, tanto nas Ciências Humanas quanto nas Exatas e Biológicas.

Se a diversidade de suportes apresenta problemas para o armazenamento, para a recuperação das informaçóes e para sua análise, dá conta, simultaneamente da complexidade das atividades administrativas, educacionais, intelectuais e políticas da Faculdade de Filosofia, retrata comemoraçôes, acidentes e crises permitindo, em alguns casos, o afloramento de novos perfis e vocaçōes inesperadas da Escola.

Ao registro da vida cotidiana e de suas transformaçóes acrescentam-se os rituais de iniciação e de passagem. A análise temporal e es- 
pacial das aparências e dos participantes recuperam lembranças ou despertam comparaçóes entre diferentes episódios.

Alguns dos planejadores, diretores e professores nos legaram livros de memórias. Nestes, como nos memoriais hoje exigidos nos concursos de professor adjunto, entre outros, descortinam-se os móveis de atração da Faculdade de Filosofia, engrenados às aspiraçóes individuais e coletivas de aperfeiçoamento ou de afastamento. Os limites irregulares e incertos da memória coletiva encontram na individualizaçăo traços mais nítidos de um passado desaparecido no presente ou diluído na consciência de identidade e participaçáo em outros grupos sociais, como a camada social e econômica, a comunidade científica ou literária ou ainda a pirâmide burocrática do Estado.

A hierarquia atual de poderes e as condiçōes econômicas da instituiçáo e de seus servidores alteram a impressão causada por questóes passadas, e os depoimentos podem corrigir e reorientar as lembranças, pois o grupo social não estabelece relaçóes e sentimentos simétricos entre os vários setores.

\section{As diferenças}

Algumas das diferenças internas devem-se ao objetivo múltiplo de seus planejadores. A Faculdade de Filosofia seria uma unidade onde se institucionaria a ciência básica, onde os estudos lingüísticos seriam aprofundados e onde se desdobraria e se adequaria uma Pedagogia que formasse professores do ensino médio.

A confusáo frequàente entre criação da Universidade e criaçăo da Faculdade de Filosofia provém de as duas terem sido criadas juntas, mas também pela vocaçáo da primitiva Faculdade de proporcionar a seus freqüentadores uma formaçáo nos diferentes campos da Universidade. A interdisciplinaridade que hoje se propóe como aspiraçáo teórico-metodológica de formaçáo cultural teve, nos primeiros tempos da Faculdade de Filosofia, condiçōes ideais de se desenvolver num encontro de jovens europeus promissores e de professores, advogados e engenheiros brasileiros ávidos de uma profissionalizaçáo consagrada por cultura humanista.

Essa diversidade de objetivos determinou as diferentes frequiências e a resultante avaliaçáo da Faculdade como um todo pelas Escolas tradicionais de: farmigerada faculdade internacional feminina de filosofia.

Como havia avaliação interna de umas seçóes pelas outras:

- estudiosos e burros vão para Geografia e História; 
- vagabundos e inteligentes vão para Filosofia e Ciências Sociais;

- estudiosos e inteligentes vão para Ciências Exatas e Biológicas;

- vagabundos e burros vão para Letras.

Depois de 1970, após a dispersão pela Cidade Universitária, seus alunos foram classificados em quatro grupos, que tanto caracterizavam os avaliados quanto os avaliadores:

- tipo militante, sabe tudo e classifica tudo;

- tipo interessado, curioso, vocaçáo para pesquisa;

- tipo indiferente, no limite, não devia ter entrado;

- tipo amorfo, está ali por não ter outra escolha.

Embora essas avaliações impressionistas façam parte do folclore da Faculdade, tiveram o seu peso nas escolhas das seçóes ou, pelo menos, no aconselhamento de jovens por parentes ou amigos da família.

\section{Os primeiros tempos}

A Faculdade iniciou as suas atividades em diferentes cenários. Matemática começou na Escola Politécnica, em seu prédio da rua Três Rios; a Casa de Arnaldo forneceu salas de aula e laboratórios para a iniciaçáo dos cursos de Ciência Sociais, Zoologia e Filosofia; a Física ficou na Brigadeiro Luiz Antonio; a compra do palacete Jorge Street, na alameda Glete, permitiu a instalaçáo da História Natural; atrás dele, construiu-se um prédio para as Químicas.

O pensamento e as práticas da nova escola entraram em conflito com as práticas dominantes nas escolas tradicionais - Medicina, Politécnica e Direito. Ao dogmatismo opunham a liberdade de criação, julgamento e crítica estimulando o conhecimento baseado em critérios científicos, no aprofundamento das especializaçóes.

Como todas as escolas dependiam de verbas do Estado, a Faculdade de Filosofia teve sua criaçáo e um começo promissor enquanto o diretor do jornal $O$ Estado de S. Paulo, planejador da Escola, "o pioneiro de uma política de cultura" (Azevedo, 1973:100-101) esteve com a situação. Assim que foi colocado na oposição, as verbas começaram a escassear, como medida para extinguir aquela fonte de despesas que conservadores e remanescentes do Partido Republicano Paulista queriam remanejar.

Depoimentos e entrevistas comprovam imagens e lembranças 
desses esforços contraditórios dos primeiros tempos. De um lado, os professores estrangeiros se desdobrando através de conferências livres, programas de cursos e de pesquisa para aperfeiçoamento nos níveis educacional, profissional e intelectual dos alunos efetivos e ouvintes das primeiras turmas. De outro, o coro dos professores nacionais preteridos, os conservadores das escolas profissionais e o governo estadual ameançado continuamente a vida da jovem escola, pelo corte de verbas. É possível que esse antagonismo em que se envolviam o grêmio estudantil, diretores, políticos e jornalistas tenha produzido a aura desse primeiro período da Faculdade de Filosofia. Apesar da dispersáo espacial, com a distribuiçáo por diversos prédios, a Sáo Paulo de 1940 era ainda atravessada de ponta a ponta por bondes abertos e fechados e ainda não tinha ruas intransitáveis. $O$ Centro ainda se chamava de $\mathrm{Ci}$ dade, onde habitantes de todos os bairros vinham fazer compras. Ainda não se tornara a Paulicéia Desvairada, nem se imaginava uma Grande São Paulo, o que facilitava a comunicaçăo e a circulaçáo de idéias.

A Faculdade de Filosofia mantinha contato com diferentes setores sociais da cidade e tinha acesso direto a seu principal jornal, cujo diretor foi paraninfo da primeira turma e frequientava aulas e corredores da Escola que conseguira criar. Por sua vez, os professores da Filosofia divulgavam pelas páginas de $O$ Estado de $S$. Paulo seus trabalhos de pesquisa e os eventos extracurriculares da Faculdade.

\section{A fase posterior}

Uma segunda fase se inicia com a oportunidade aberta a professores primários de serem comissionados para fazer os cursos da Faculdade e a ocupaçáo do $3^{\circ}$ andar da Escola Normal Caetano de Campos, na praça da República, pela diretoria, administração e grêmio estudantil, utilizando saláo nobre, salas de aulas e de professores, entre outras dependências.

A dispersão ainda continuava pela rua Sáo Luiz, pela Brigadeiro Luiz Antônio. Contudo, o Grêmio, extremamente ativo, publicando uma Revista com trabalhos de professores e alunos, organizando cursos preparatórios para o Vestibular, grupo teatral e clube de cinema, funcionava como centro de atração e promovia a convergência dos alunos de Ciências Exatas e Biológicas para aquela praça, cenário de tantas fotografias de casais e grupos de alunos pelos fotógrafos lambe-lambe que a povoavam.

Os alunos desse terceiro andar ficavam próximos da Biblioteca Municipal - antes na 7 de Abril, depois na Consolaçáo -, do Teatro Municipal e a pequena distância do largo de São Francisco e da Facul- 
dade de Direito, com sua preciosa biblioteca, e dos sebos das ruas transversais. As praça Ramos de Azevedo e do Patriarca, nas duas extremidades do Viaduto do Chá, eram locais onde confluíam ônibus e bondes de todos os bairros paulistanos.

É inevitável que esses quadros sociais do passado apareçam sempre nas comparaçóes com a Faculdade de Filosofia de hoje. A tendência de cada depoimento é de recuperar fatos, crenças e necessidades antigas em sua relação com as atuais. Essa recuperação, em alguns casos, reveste-se de grande saudosismo, quando se esquecem as rupturas, as dificuldades e as decepções. Em outros, a recuperação náo é tão seletiva e permite restabelecer um quadro menos deformado, no qual entram circunstâncias e relaçóes felizes e infelizes com a populaçáo, com o governo, com as escolas tradicionais no desenvolvimento da Faculdade e na formação cultural e científica oferecida.

Foram poucos os que se recusaram a fazer esse trabalho de rememoração por ressentimento acumulado ou necessidade de esquecer passagens difíceis de sua biografia. As memórias e os memoriais transcritos, ou copiados, tecem uma trama contínua com o trabalho de recuperação e redefinição de uma experiência individual, que se apóia na reconstrução de outros, de percurso pelos mesmos lugares em um mesmo momento, ao perceber as diferenças do cotidiano e de suas rupturas.

A oportunidade para transmitir a experiência pessoal e refletir sobre ela tem proporcionado satisfação renovada à entrevistadora $e$ aos entrevistados, à medida em que representa alteraçáo e aperfeiçoamento de conhecimento, através da renovaçáo de encontros e desencontros, numa etapa da vida na Faculdade de Filosofia. A açáo destruidora do tempo pode ter o efeito paradoxal de destacar e articular novas condiçóes sociais, econômicas e científicas dos espaços e das condiçôes de vida pessoal e profissional de seus contemporâneos. $O$ agrado com o re-visto, com o re-conhecimento e a re-assegurança tira do trabalho de recuperaçáo o desinteresse da imagem sem dimensão temporal e permite associações e vocaçóes de circunstâncias conjunturais que são trazidas para 0 presente.

Nessa fase, 1940-1950, ligada à praça da República, já se implantaram'novas atitudes de trabalho intelectual, de rigor e espírito crítico nas ciências e nas letras e a crença em que somente as verdadeiras mentes científicas suportam as dúvidas inerentes a todo conhecimento. A politização foi se acentuando com o fim da Segunda Guerra Mundial e do Estado Novo.

Convém também "lembrar que a opinião que temos uns dos ou- 
tros, as relaçóes de amizade, de família só são fixas na aparência", estão sempre se alterando, "auxiliadas pelas desagregaçóes contínuas do esquecimento, numa vida que é feita de uma renovaçáo perpétua de células" (Proust, Le Cott de Guermantes I:261; Albertine Disparue II:64 e 163).

\section{A heterogeneidade}

A população da Faculdade está longe de ter traços homogêneos. Além da dispersão por vários locais, em número diferente, outra diversidade foi se acentuando com a explosão populacional. Consta de alunos, professores e funcionários que, enquanto em pequeno número, mantinham contatos personalizados e comungavam em algumas aspiraçōes. Houve muitos casos, nos tempos da Faculdade de Medicina e da praça da República, em que alunos exerciam trabalhos técnicos e administrativos e funcionários auxiliavam pessoalmente os professores estrangeiros. Com o crescimento da populaçáo, acentuaram-se as fronteiras entre as três faixas. Com raras exceçóes, os alunos tinham um convívio de três e quatro anos e, após esse período, ou passavam para a categoria de monitores e professores, ou desapareciam nas redes do ensino secundário que foram se estabelecendo no interior do estado e pelo resto do Brasil. Os funcionários, mantidos em suas funçóes por décadas, estavam táo ligados à Faculdade que, em inúmeros casos, eram associados pelos calouros com a Escola e funcionavam como mensageiros entre as três populaçōes. Entre os professores estrangeiros, contratados inicialmente como visitantes, alguns permaneceram e constituíram família no Brasil. Outros voltaram para seus países de origem depois do fim da guerra de 1939-1945; tinham preparado, entre seus alunos, os assistentes que deveriam assumir os encargos após a sua retirada. Muitos desses assistentes fizeram suas carreiras na Faculdade e alguns chegaram a formar dinastia, quando filhos ou assistentes e auxiliares de ensino percorriam as pegadas do mestre.

O número de alunos, diminuto nos primeiros anos, foi crescendo até superar as vagas existentes. Esse aumento foi paralelo ao crescimento vertiginoso de Sáo Paulo, nos anos de pós-guerra e à melhor integração da Faculdade entre as escolas da Universidade. As instalaçóes funcionavam em turnos para abrigar as classes das diferentes subseçōes.

\section{A centralização e a descentralização}

Em 1949, muitas seções de Ciências e Letras reuniram-se nos prédios do antigo Liceu Rio Branco, na rua Maria Antônia, comprados pelo governo estadual.

Durante 20 anos, uma segunda geraçáo de alunos lá viveu em 
comunidade integrada que os marcou profundamente. Depoimentos, panfletos e livros assinalam a formaçáo, o fervor, a interdisciplinaridade, a politizaçáo e o desenvolvimento de um espírito corporativo que tornavam os alunos e agregados da Maria Antônia responsáveis pela emancipação do povo brasileiro de suas mazelas coloniais.

A invasão da Maria Antônia por membros do Comitê de Caça aos Comunistas estimulados pela repressão militar que já cassara arbitrariamente mestres e alunos destacados, concorreu ainda mais para que a Maria Antônia se transformasse no paraíso perdido.

Com a invasáo, a Faculdade se desmembrou novamente. Alguns foram para os poucos prédios prontos numa Cidade Universitária lamacenta e deserta, outros voltaram a pedir abrigo às escolas já instaladas. Os prédios da Maria Antônia, muito danificados, foram interditados e cedidos pelo governo à Junta Comercial.

Vinte anos depois, quando as instalaçóes da Filosofia voltaram às mãos da Universidade, seus antigos ocupantes, agora professores titulares e livre-docentes, percorriam surpresos o prédio, do poráo ao $4^{\circ}$ andar, murmurando: "Como é pequeno! Será possível que aqui coubéssemos todos? Ainda o grêmio e a biblioteca?"

Os vinte anos passados tinham transformado inteiramente a Faculdade, desde o nome. A Reforma de 1969 , contra a qual os alunos tanto tinham se batido, foi implantada. As Ciências Exatas, as Biológicas, e a Psicologia se emanciparam em Institutos novos e estruturou-se uma Faculdade de Educação. A Faculdade se tornou Faculdade de Filosofia, Letras e Ciências Humanas, prejudicada, segundo alguns, em instalaçōes fechadas por barrancos, para que náo pudesse crescer. Durante o período da Maria Antônia, ela se impusera à Universidade pelo brilho e destemor de seus professores e alunos. A reforma de 1969, alterando a graduação e a pós-graduação, de acordo com o modelo norte-americano, implantando os cursos semestrais e alterando o primitivo esquema arquitetônico, conseguiu dissolver as turmas anuais, a unidade e a integração dos diferentes departamentos. $O$ distanciamento do centro da Cidade cumpriu também o papel que a repressáo militar impusera à Universidade.

O número de vagas para vestibulandos aumentou, as exigências para $O$ ingresso diminuíram e mesmo aqueles que cursaram insistentemente os semestres letivos, dificilmente eram alunos que se enturmavam, como tinham feito seus professores. As classes de oitenta e cem alunos impediam contato pessoal produtivo, mesmo porque certo número de alunos ia abandonando o curso no decorrer do semestre. 
Durante os vinte anos de repressão Militar os informantes da polícia, infiltrados entre os alunos e funcionários, criaram um ambiente de suspeita que mal permitia o estabelecimento de relaçōes cordiais. Os funcionários técnicos e administrativos foram estimulados a denunciar o que havia de suspeito, através de benefícios na carreira.

Como na maioria dos cursos superiores, o nível cultural baixou; embora a Cidade Universitária tenha se povoado, a indústria automobilística tenha enchido os estacionamentos e os caminhos que a ela dáo acesso, a produçáo de teses, de revistas e de coleçóes tenha atingindo altos níveis, o distanciamento entre os departamentos se estabeleceu, não só nas instalaçóes, mas também na formação e nos objetivos de alunos, funcionários e professores. Burocratização crescente passou a bloquear o trabalho científico e a autonomia universitária resultou na transferência das lutas por verbas para o interior da Cidade Universitária.

As instituiçóes de financiamento, além de rejeitar pesquisa sem aplicaçáo imediata, consomem o tempo do pesquisador em relatórios cada vez mais complexos, e a obediência a regimentos e regulamentos vem deformando ou suprimindo a liberdade criadora, com as exceçóes de praxe.

O espaço na Cidade Universitária foi disputado como insignia de poder - houve mesmo quem expressasse sua trajetória acadêmica em termos de metros quadrados acrescentados às salas e laboratórios de cada disciplina.

"Quando deslizamos o acontecimento sob as lentes de aumento da memória, estas lhe dão relevo, divisóes, recuo de superfície e perspectiva em diferentes pontos do espaço e do tempo o que, para os que não viveram a época parece ligado a uma única superfície: os nomes dos mortos, os sucessivos endereços, as origens e as oscilaçōes da sorte, as mutaçóes de propriedade" (Proust, Albertine Disparue II:64).

\section{O desdobramento}

A utopia sonhada com diferentes feitios desde 1934 foi se materializando, ganhando dimensóes gigantescas e desdobramentos cada vez mais complexos, que acabaram asfixiando os primeiros objetivos da Universidade.

O departamento de Letras e Lingüística desdobrou-se em vários setores, o de Ciências Sociais passou a ter departamentos separados de Sociologia, de Antropologia e de Política e os de História e Geografia, unidos pelo prédio, estão a estudar divisóes internas. 
Enquanto até as Ciências Exatas e Biológicas consideram a impossibilidade de aprofundamento do conhecimento sem a interdisciplinaridade, as condiçóes materiais do ensino e da pesquisa vêm se fragmentando ou paralisando os trabalhos transdisciplinares com que sonharam os fundadores da Faculdade de Filosofia.

Com inúmeros recuos e incontáveis avanços chegou-se aos sessenta anos da Faculdade de Filosofia e da Universidade de São Paulo. O papel destacado que a Faculdade desempenhou na resistência à repressáo militar e na liderança do movimento estudantil, bem como pelo acesso de seus melhores elementos a responsabilidades nacionais e internacionais foi alterado após 1970 e em sua dispersão pela Cidade Universitária.

Hoje, a fragmentaçáo do ensino e da pesquisa na graduaçáo vem sendo compensada pela formação de Grupos de Trabalho Temáticos, por Centros e Núcleos de Estudos às vezes de caráter regional e nacional, que reúnem cientistas e estudiosos de diferentes áreas, procurando refazer condiçóes de superar a compartimentaçáo das disciplinas acadêmicas. A multiplicaçăo de escolas de 3ำ grau não é suficiente para assegurar um mercado de trabalho para os formados, que precisam se garantir com bolsas e títulos acadêmicos, mesmo sem ter qualificações ou pendor para a pesquisa científica.

Dentro desta situaçáo de ser uma Universidade rica dentro de um país pobre e desesperançado, formando pessoas altamente qualificadas que não encontram colocaçáo e disputam, às dezenas, as vagas que se abrem, mesmo mal remuneradas na Universidade, este exercício de memorização confirma avanços e um aproveitamento de vocaçóes que se desdobrou pela populaçáo de todo o Brasil.

\section{Referencias bibliografficas}

AZEVEDO, Femando de. Histrria de minba vida. Rio de Janeiro, Jose Olympio; Săo Paulo, Conselho Estadual de Cultura, 1971.

Figuras de mene contrio (retratos de fumalin, de mestres e educadores). 2. ed. Săo Paulo, Duas Cidades, 1973.

BOSI, Ecléa. Lembrangas de vellbos. Sāo Paulo, T.A. Queiroz, 1979.

HALBWACHS, Maurice. A momoria coletipa; trad. de Laurent Leon Schaffter. Săo Paulo, Vértice/Revista dos Tribunats, 1990. 
DUARTE, Paulo. O processo dos rinocerontes (raztes de defiesn e outras rastés...) Sáo Paulo, s/ed., 1967.

PROUST, Marcel. À la recherche du temps perdu. Paris, Gallimard, 1919-1927.

Merimen Lifibitz Moreira Inite te pesquisadora e trabalha no Centro de Apoio à Pesquisa em História (CAPH) desde 1975. Na coordenaçáo do Projeto Memória da Faculdade de Filosofia, iniciado em 1982, teve a oportunidade de aprofundar seus estudos sobre a Memória (individual e coletiva) cuja documentaçăo tem fornecido subsidios a Estudos Apangeudos. 